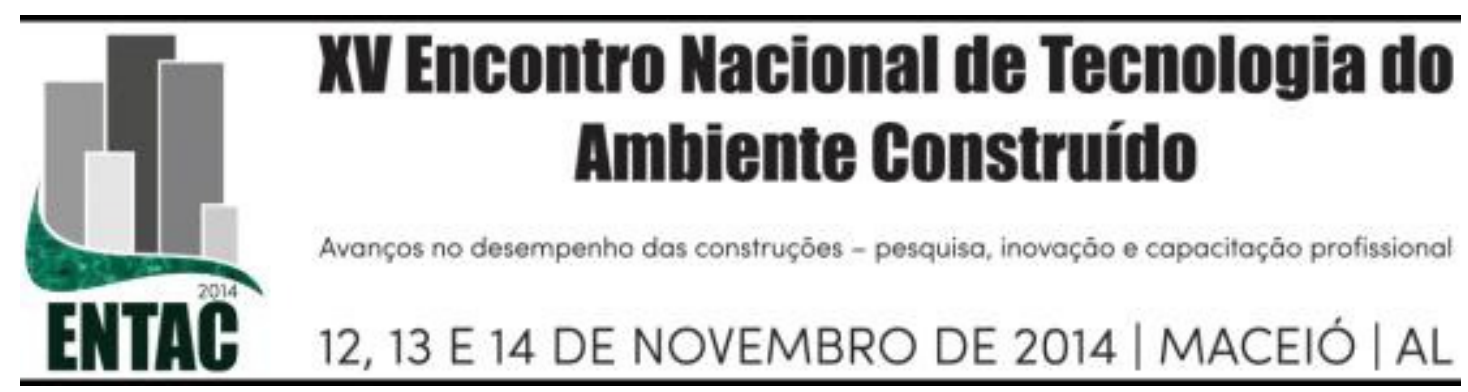

\title{
BARREIRAS PARA APLICAÇÃO DO CONCEITO DE FLEXIBILIDADE ESPACIAL EM PROJETOS DE HIS NO BRASIL
}

\author{
COSTA, Heliara A. (1); BRANDÃO, Douglas Queiroz (2) \\ (1) Universidade Federal de Mato Grosso, e-mail: heliaracosta@gmail.com \\ (2) Universidade Federal de Mato Grosso, e-mail: dbrandao@ufmt.br
}

\begin{abstract}
RESUMO
Além da baixa qualidade tecnológica e de materiais, as habitações de interesse social no Brasil possuem, quase sempre, uma má qualidade dos espaços ofertados. Maior parte das críticas são feitas para projetos concebidos de forma extremamente funcional, com espaços reduzidos, padronizados, priorizando custos baixos, sem considerar a opinião dos moradores, composições familiares, comportamentos e necessidades atuais e futuras de usos. Com características rígidas, as alterações para adaptação ocorrem por meio de onerosas e complicadas reformas, quase sempre com impactos negativos na estética e funcionalidade do espaço. Entretanto, estudos demonstram o conceito de flexibilidade espacial como alternativa vantajosa na personalização da moradia, além de ser critério para qualidade de projeto. Esta pesquisa objetiva identificar as barreiras para aplicação do conceito de flexibilidade espacial em projetos de habitações de interesse social no Brasil. O método de investigação baseia-se em uma revisão bibliográfica e entrevista com professores pesquisadores sobre o tema, com objetivo exploratório. Os resultados parciais obtidos apontam que as barreiras ocorrem devido à: qualificação profissional, falta de interesse em habitação de interesse social/falta de sensibilidade, controle urbano, redução do papel do arquiteto, lacuna entre morador e arquiteto, leis e normas, questões financeiras, culturais, ausência de inovação tecnológica, interferências políticas. A identificação das barreiras nesta fase preliminar possibilitou obter subsídios para etapas subsequentes da pesquisa. Os resultados também contribuem para a difusão do conteúdo e despertam a atenção dos envolvidos na produção dessas edificações para o conceito de flexibilidade.
\end{abstract}

Palavras-chave: Habitação de interesse social, Flexibilidade Espacial, Personalização, Qualidade do projeto habitacional.

\begin{abstract}
Besides the low quality technology and materials, social housing in Brazil has always a bad quality of the offered spaces. Most of these criticisms are made to projects designed extremely functional, with reduced standardized spaces, prioritizing low costs, without considering the views of residents, family compositions, behaviors and needs of current and future uses. With rigid characteristics, adaptation to the changes occurs through costly and complicated reforms, often with negative effects on aesthetics and functionality of the space impacts. However, studies have demonstrated the concept of spatial flexibility in customization as advantageous alternative housing, as well as being a criterion for quality design. This research aims to identify barriers to implementation of the concept of spatial flexibility in projects of social housing in Brazil. The research method is based on a literature review and interviews with faculty researchers on the topic, with exploratory objective. Partial results indicate that barriers occur due to: professional qualifications, laziness, lack of interest in social housing/insensitivity, urban control, reducing the role of the architect, gap between resident and architect, laws and regulations, issues financial, cultural, lack of technological innovation, political interference. The identification of barriers at this preliminary stage allowed obtaining grants for subsequent stages of the research. The results also contribute to the dissemination of content and attract the attention of those involved in the production of these buildings to the concept of flexibility.
\end{abstract}

Keywords: Social Housing, Spatial Flexibility, Customization, Quality housing project. 


\section{INTRODUÇÃO}

Cálculos do Ministério das Cidades em parceria com a Fundação João Pinheiro, tendo como base Pesquisa Nacional por Amostra de Domicílios de 2007, apontam um déficit 6,273 milhões de domicílios e atinge principalmente a população com renda de até três salários, na faixa superior a $60 \%$ em todas as regiões brasileiras. A política para combater esse déficit associada à sistemática de redução de custos promove, normalmente, a construção de conjuntos residenciais cujas habitações seguem o modelo industrial: massificada, em série e padronizadas. Barcelos (2011) afirma que isso levou a uma redução da área das unidades.

O problema vai além do tamanho da moradia. Afetam fatores como qualidade do espaço, o arranjo espacial (BARCELOS, 2011). São habitações, na maior parte das vezes, impessoais, o que impossibilita o estabelecimento de relações entre o usuário e a edificação (SZÜCS, 1998; SILVEIRA; RAMOS, 2000 apud MARROQUIM; BARBIRATO, 2007). Isso faz com que o usuário busque por conta própria personalizar sua moradia, muitas vezes dificultada por questões de ordem técnica, econômica, acarretando-lhe prejuízos em diversos níveis (MEIRA; SANTOS, 1998).

Os motivos para tais mudanças estão relacionados ao caráter funcional, simbólico ou econômico, evidência da falta de sintonia entre o projeto e os anseios dos futuros moradores. Na maior parte das vezes, ocorrem por necessidade de ampliação de espaço, como a criação de quartos extras, mais espaço na sala ou cozinha, e agregação de varandas e garagens. Essas modificações impactam negativamente na funcionalidade, na habitabilidade e na harmonia estético-arquitetônica (BRANDÃO, 2011).

Por outro lado, responder isoladamente aos anseios de cada família é uma proposta impensável para a indústria da construção brasileira. Essa personalização tornaria o processo de produção caro e inviável. A concepção de projetos que contemplem estratégias de flexibilidade é uma das alternativas para esta situação apontada por diversos autores. De acordo com Brandão (2011), a flexibilidade tem sido enfatizada no Brasil em vários estudos realizados sobre o mercado da construção civil brasileira. Alguns exemplos são: Brandão (1997; 2002), Campanholo (1999), Círico (2001), Moschen (2003), Digiacomo (2004), Carvalho (2004), Payeras (2005), Szücs et al. (2006), Marroquim e Barbirato (2007), Tillmann (2008), Finkelstein (2009), Strapasson (2011), Weinschenck (2012) e Jorge (2012). Os estudos apontam principalmente para a flexibilidade de execução, com a construção em etapas; e flexibilidade de uso, com adequação dos espaços às necessidades do habitante, incluindo acessibilidade. No entanto, as habitações de interesse social brasileiras das últimas décadas não contemplam estratégias flexíveis, com raríssimas exceções.

Num cenário capitalista, o senso comum aponta o custo de produção como barreira ao emprego desse modelo no país. No entanto, outros países têm demonstrado a viabilidade financeira de habitações sociais flexíveis, construídas com tecnologias e materiais tradicionais e boa aceitação do público. Desta forma, esta pesquisa objetiva identificar as barreiras para aplicação do conceito de flexibilidade espacial em projetos de arquitetura para habitações de interesse social no Brasil.

\section{FUNDAMENTAÇÃO TEÓRICA}

\subsection{Arquitetura flexível: conceito, classificações e estratégias}

O conceito de flexibilidade na arquitetura é a capacidade do espaço físico se adaptar ao processo dinâmico do habitar. Tal conceito é interpretado de forma variada, por diversos 
autores. Para Joedicke (1979), um projeto flexível é aquele que permite projetos espaciais variados, por meio de usos e ampliações, sem alterações na edificação original ou que estas sejam inviáveis. Digiacomo (2004) afirma que a flexibilidade é a capacidade do espaço físico se adaptar com facilidade às necessidades e desejos de seus ocupantes. Scheneider e Till (2005) definem habitação flexível como sendo aquela cuja concepção permite alterações durante sua vida útil. Szücs et al. (2006) coloca como a possibilidade de modificar a função da habitação sem modificar as partes construídas. Nota-se que os conceitos são variados. Estão atrelados às suas estratégias, o que por vezes gera certa confusão. Na definição de Galfetti (1997 apud Brandão, 2011), flexibilidade é o grau de liberdade que torna possível a diversidade de modos de vida. Para Abreu e Heitor (2007) a condição adaptativa do espaço físico da habitação resulta da aplicação de estratégias projetuais, tanto ao nível da organização espacial, como dos processos construtivos. Brandão (2002) identificou e agrupou termos usados na literatura sobre as variadas denominações para flexibilidade, definindo a forma de aplicação de cada uma. A análise estabeleceu cinco grupos fundamentais:

Diversidade tipológica: pré-concepção de plantas diferentes, com diversidade de unidades-tipo em um mesmo edifício.

Flexibilidade propriamente dita: inclui técnicas de rápida e fácil conversão ou transformação com promoção de economia, embora seja necessária intervenção construtiva.

Adaptabilidade: a função é definida por meio do mobiliário, divisórias móveis ou pela versatilidade na utilização do mobiliário. Possibilita funções simultâneas para o mesmo ambiente.

Ampliabilidade: oferece opções de ampliar a casa mínima ou a habitação-embrião. É forma de habitação evolutiva. Estratégia que também é conhecida como elasticidade.

Junção/desmembramento: casos de junção de duas unidades residenciais para formar uma maior e também o caso contrário, quando uma unidade é desmembrada em duas.

Há ainda definições quanto ao momento em que ocorre, que pode ser pode ser inicial ou contínua. Sebestyen (1978 apud BRANDÃO; HEINECK, 1997) define como um conjunto de soluções de projeto e técnicas que permitem alterações pelo projetista e pelo morador, no momento de concepção da habitação, por meio de um número relativo de possibilidades em planta. Permite ao usuário adaptar os espaços sem alterar ou deslocar a estrutura portante da edificação. Pode ser subdividida em: mobilidade, evolução e elasticidade.

Em relação à oferta do mercado imobiliário, a flexibilidade pode ser permitida ou planejada. Flexibilidade permitida é capacidade de alterar ou personalizar o projeto a partir de uma única opção inicial. É oferecida pelo construtor ou vendedor, normalmente a partir de pressões e exigências do mercado competitivo. A flexibilidade planejada é a ofertada por meio de leiautes alternativos pela empresa vendedora ou construtora. São oferecidas opões de plantas e acabamentos para um mesmo imóvel (BRANDÃO, 2007).

Galfetti (1997 apud Brandão 2007) fala em flexibilidade leve (ou realística) associada às tecnologias low-tech (sistemas abertos) em contraposição à high tech. Desta forma, também pode-se considerar uma classificação da flexibilidade quanto à tecnologia usada em seus operadores. De acordo com o autor, fabricantes, construtores e usuários, que preferem as tecnologias simples (low-tech) no que se refere à construção residencial. 


\subsection{Razões para uma arquitetura flexível}

Brandão (2011) coloca que a qualidade da habitação manifesta-se por atributos físicos e psicológicos. A necessidade de personalização mostra que as pessoas possuem necessidades e desejos próprios, por isso pedem projeto de habitações com soluções customizadas. No entanto, há muito mais razões que justificam a proposição de um espaço flexível de moradia. A sociedade globalizada sofre mudanças rápidas e não existe mais uma cultura única e permanente. E a indústria tem buscado cada vez mais se adaptar ao novo modelo.

No contexto familiar, existem as mudanças nos relacionamentos e o surgimento de novos arranjos familiares. "O conceito de família nuclear (com pais e filhos na mesma casa) não é mais suficiente. Há arranjos domésticos sem nenhum padrão." (BILAC, 2011). No Brasil, até os anos 80,70\% das famílias eram nucleares. Atualmente, menos da metade é desta forma. Os meios de comunicação, a legislação - com a lei divórcio e o direito a um novo casamento -, conquistas da mulher, como direitos iguais, poder de decisão nos lares e acesso ao mercado de trabalho; casamento gay estão entre os grandes responsáveis pelos novos tipos de composições de família e novos arranjos domiciliares, que não envolvem necessariamente laços de parentesco (CARVALHO, 2009). Alguns dos novos arranjos citados por Carvalho (2009) são: Lat (living apart together), casais que vivem juntos separados; Dink (double income no kids), casais que tem dupla renda sem filhos. Há ainda pessoas que vivem só; diminuição do número de filhos; famílias que se tornam menores por conta do casamento dos filhos; casais com filhos de vários casamentos; entre outros.

Aliado a esses fatores, há questões comportamentais, com maior individualização das formas de viver, necessidade de territorialização do espaço; criação de identidade com o lugar; diferenciação social; aspectos funcionais (Brandão, 2011). O aumento da longevidade da população tem levado máquinas e equipamentos para dentro dos lares e feito surgir novos ambientes, especialmente projetados para este fim (home care). Cada vez mais, os espaços de trabalho (home office) estão nos interiores das habitações. Permeiam essas mudanças as novas tecnologias de comunicação e a consequente transculturalidade.

Apesar desses fatores, os projetos de habitação de interesse social brasileiros são concebidos de forma padronizada, para um usuário com características, gostos e necessidades idênticas. São ambientes reduzidos e altamente especializados. A esse respeito Kapp (2007) denomina esse fenômeno como a "síndrome do estojo". A autora cita Walter Benjamin, que certa vez caracterizou a moradia burguesa do século XIX como um estojo, aquele tipo em que se guardavam instrumentos com precisão, com o espaço em baixo relevo exatamente para aquele objeto - e que não admite outra função, exceto para a qual foi criada.

\section{MÉTODO}

\subsection{Procedimentos metodológicos}

O método de investigação deste estudo teve como base uma pesquisa bibliográfica e entrevistas com intervenientes no processo de construção. Neste momento, de forma exploratória, foram realizadas entrevistas com intervenientes indiretos: professores pesquisadores sobre o tema, ou seja, foram abordados somente formadores de opinião e de conhecimento.

Na parte bibliográfica, buscou-se a revisão sobre o tema em obras publicadas em plataformas de instituições e eventos. Para as entrevistas, foram selecionados professores pesquisadores sobre habitação flexível e habitação de interesse social, priorizando o nível 
de doutorado. Foi elaborado um questionário por meio de um sistema virtual, enviado por internet, com uma única pergunta: "Em sua opinião, quais as barreiras para que o conceito de flexibilidade na arquitetura seja pouco aplicado em projetos para habitações de interesse social no Brasil?" Por se tratar de uma pesquisa qualitativa, o propósito foi deixar a questão em aberto e dar o maior grau de liberdade possível nas respostas. Desta forma, um único entrevistado pode emitir opinião relacionada a vários fatores. E também para não desestimular o entrevistado, com várias questões. Foram enviados 75 questionários, e obtidas 17 respostas, o que foi considerado suficiente para uma pesquisa de natureza exploratória.

\section{RESULTADOS E DISCUSSÃO}

As duas fontes de pesquisa consultadas apresentam argumentos para barreiras na aplicação dos conceitos de flexibilidade bastante relevantes. O quadro a seguir apresenta uma síntese do resultado das questões mencionadas na bibliografia e nas respostas dadas aos questionários enviados. A maior parte das barreiras foi citada pelas duas fontes. $\mathrm{Na}$ literatura não foram encontradas as barreiras: falta de interesse em geral; falta de interesse em HIS/falta de sensibilidade e controle urbano.

Quadro 1 - Barreiras apontadas na literatura e nas entrevistas

\begin{tabular}{|l|c|c|}
\hline \multicolumn{1}{|c|}{ Barreiras } & Literatura & Entrevistas \\
\hline Má qualificação profissional & $\mathrm{x}$ & $\mathrm{x}$ \\
\hline Falta de interesse em geral & - & $\mathrm{x}$ \\
\hline Falta de interesse em HIS/Falta de sensibilidade & - & $\mathrm{x}$ \\
\hline Controle urbano & - & $\mathrm{x}$ \\
\hline Redução do papel do arquiteto & $\mathrm{x}$ & $\mathrm{x}$ \\
\hline Lacuna entre o arquiteto e o usuário final & $\mathrm{x}$ & $\mathrm{x}$ \\
\hline Funcionalidade imposta por leis e normas & $\mathrm{x}$ & $\mathrm{x}$ \\
\hline Questões financeiras & $\mathrm{x}$ & $\mathrm{x}$ \\
\hline Ausência de inovação tecnológica & $\mathrm{x}$ & $\mathrm{x}$ \\
\hline Questões culturais & $\mathrm{x}$ & $\mathrm{x}$ \\
\hline Interferências políticas & $\mathrm{x}$ & $\mathrm{x}$ \\
\hline
\end{tabular}

Fonte: autor, 2014

Qualificação profissional: este tópico foi um dos mais citados. Na literatura, Strapasson (2011) relata a não familiaridade da temática na formação dos profissionais como uma barreira. Tramontano (1998) afirma que arquitetos são preparados para reproduzir modelos existentes. Os entrevistados - professores arquitetos e engenheiros - veem problemas no currículo dos cursos de arquitetura do país, que dão pouca ou nenhuma ênfase sobre habitação flexível e inovação em projetos. A má formação dos profissionais também é citada no que tange à capacidade de gestão de processo de projeto, conhecimento sobre estágio de ciclo de vida e comportamento humano e capacidade de pensar a partir de modelos espaciais. Além da qualificação do projetista, foi citada também a má qualidade da mão de obra de execução. Relatam ainda que o ensino de projeto nas faculdades ocorre de forma desconectada do contexto urbano e que habitação de interesse social constitui assunto pouco estudado.

Falta de interesse: o projetista "não está interessado em debruçar sobre o projeto", afirma um dos entrevistados. Também foi relatado que há uma complexidade projetual na arquitetura flexível que não é de interesse dos arquitetos. Há também uma falta de 
interesse pelo usuário, que não é o seu cliente final. Por parte do construtor, não existe preocupação com manutenção e ampliações futuras.

Falta de interesse em habitação de interesse social/falta de sensibilidade: especialmente em relação ao público de menor renda. A falta de sensibilidade ou interesse nesta parcela do público citada, está relacionada ao fato de no Brasil, infelizmente, arquitetura ser um produto caro e arquitetos entram e saem dos cursos com uma visão equivocada da profissão. Querem projetar para condomínios luxuosos e para as classes mais altas da sociedade.

Controle urbano: os entrevistados relatam que as habitações evolutivas e inacabadas podem sofrer preconceito, com imagem de espaço deteriorado ou "favelização", levando a uma desvalorização imobiliária do entorno.

Redução do papel do arquiteto: para Tramontano (2006), a decisão dos projetos sai da esfera do arquiteto e ganha espaço no estande de venda na São Paulo dos anos 20, período da consolidação e profissionalização do mercado imobiliário e da elite cafeeira. Os projetos passam a ser decididos por objetivos comerciais, que nem sempre representam as verdadeiras aspirações dos compradores. Os entrevistados corroboram essa afirmação. Alegam que a decisão do projeto foi transferida para as regras do mercado imobiliário.

Lacuna entre morador e arquiteto: a falta de diálogo entre quem concebe e quem usa é um dos fatores que barram o desenvolvimento de uma arquitetura flexível para HIS. Barcelos (2011) comenta que cabe aos usuários confiar no analista de projetos das instituições intervenientes. Leite, Schramm e Formoso (2006) afirmam que o cliente que mais influência nos requisitos de projeto e produção é a Caixa Econômica Federal. Esta questão aparece parcialmente nas respostas dadas pelos entrevistados ao relatarem o desinteresse de quem projeta e constrói para o usuário final.

Leis e normas: configuram entre as barreiras normas, leis e exigências dos intervenientes. A Caixa Econômica Federal, o código de obras das cidades (KAPP, 2013) e a NBR 15.575 exigem configurações espaciais ainda muito funcionalistas. Os entrevistados revelam que as normas e leis são muito restritivas, embora não cite a funcionalidade de forma expressa. É citado também a falta de exigência por parte dos órgãos financiadores da implementação da flexibilidade como critério de desempenho mínimo das habitações.

Questões financeiras: o conceito de flexibilidade é contraditório aos interesses de mercado. Para Brandão (2006), casas flexíveis são mais caras por apresentar índices de compacidade menores, maiores relações entre os planos verticais por área construída e superprovisão de sistemas e materiais. Estudos de Schneider e Till (2005) indicam que o barateamento ocorre a longo prazo e não para o construtor. Nas entrevistas, a questão financeira é colocada sob diversos aspectos: alto custo do terreno, limitante à habitação evolutiva; porque os projetos flexíveis demandam tempo no processo de projeção, construção e, principalmente, de participação da comunidade de interesse. É considerada perda de tempo (e dinheiro) explicar aos beneficiários as vantagens de um sistema aberto, ainda que tenha um pior visual. Para a maior parte dos professores, construtoras estão interessadas em fazer o que parece mais rápido e fácil, com foco na quantidade e não qualidade.

Culturais: Brandão (2002) afirma que as casas populares, nas primeiras décadas do século $\mathrm{XX}$, constituíam-se em conjuntos precários e se utilizavam de operadores flexíveis, com divisões internas feitas por cortinas, móveis e painéis de madeira. Para muitos, transmitia uma imagem de precariedade e então passou a ser rejeitada. "É provável que esta imagem de precariedade associada à miséria material, represente características que as casas duráveis das pessoas com algum êxito social jamais deveriam expressar."(BRANDÃO, 
2002). A questão cultural foi colocada pelos entrevistados sob um viés diferente. Para alguns, a cultura da casa pronta é valorizada no país, considerada como um valor agregado ao produto habitacional. Refere-se a uma possível rejeição a "meia casa pronta", nos moldes das habitações evolutivas construídas no Chile pelo escritório Elemental (ARAVENA, 2004).

Ausência de inovação tecnológica: algumas soluções de projeto e operadores de flexibilidade exigem inovação tecnológica que o setor construtivo brasileiro não está disposto a investir para habitações de interesse social. Foi citado nas entrevistas a ausência de componentes e subsistemas orientados à flexibilidade e adequados à realidade econômica da habitação de interesse social. Alguns concordam que o morador deveria contar com soluções "faça você mesmo" no período pós-ocupação, possibilitando a estes ampliar suas moradias. Foi também relatado a inexistência de mobiliários flexíveis à venda nas lojas.

Interferências políticas: Aravena (2012), arquiteto do projeto evolutivo Quinta Monroy, Chile, afirma que o maior problema do Brasil na construção de habitações flexíveis envolve questões políticas. Relatou a experiência no desenvolvimento de um projeto flexível para Paraisópolis, em São Paulo, em 2008. A proposta foi recusada por representar ganhos menores para as construtoras. $\mathrm{O}$ arquiteto também participou da pesquisa via internet e apresentou três questões políticas que considera empecilho à construção de habitações evolutivas no país: 1) Uma obra inacabada (para evoluir) não gera boa propaganda política; 2) Política de subsídio voltada para a oferta e não para a demanda; 3) Impactos na redução das taxas de empregos formais do país. A questão da propaganda se reflete na imagem do conjunto. "Um político em posição de poder prefere entregar algo pequeno e de menor qualidade, mas que nas fotos $(\mathrm{e}$, portanto, frente à opinião pública) se vê terminado". Sobre política de subsídio, considera que há um lobby das construtoras e uma pressão para assinatura de contratos com valores o mais alto possível. "Sistemas abertos e flexíveis deixam parte dos recursos fora da mesa das grandes construtoras e não convém às grandes licitações". E por último, deixar que as pessoas concluam suas casas por conta própria pode impactar nos registros sobre as taxas de empregos formais no país, uma vez que o setor da construção civil é um dos que mais tem contribuído para a geração de empregos no Brasil. "Um sistema flexível, em que cada família pode adaptar sua casa, é muito bom para cada cidadão, porém invisível aos indicadores macroeconômicos." Essas barreiras não são exclusivas do Brasil, finaliza Aravena.

\section{CONSIDERAÇÕES FINAIS}

Este estudo revisa a importância do uso do conceito de flexibilidade na arquitetura, especialmente em projetos de habitação de interesse social. Os requisitos da arquitetura flexível promovem uma série vantagens na pós-ocupação dessas edificações, momento em se tem início a relação do usuário com a moradia. Essa relação se dá pela real apropriação da moradia, por meio da personalização do espaço para atender às suas necessidades funcionais e seus desejos simbólicos. Normalmente, por ampliação do espaço, determinação de novas funções aos ambientes, como a sala de estar que se integra à cozinha, mais quartos para os filhos, novas cores, entre outros.

Essas mudanças ocorrem com alto custo de reforma, com derrubadas de paredes, mudanças de portas de janelas de local. Seria mais simples e barato se esse processo de apropriação fosse programado no projeto arquitetônico, o que infelizmente não tem ocorrido com frequência no país. 
As barreiras apresentadas para que as estratégias de flexibilidade sejam adotadas nos projetos são: má qualificação profissional; falta de interesse em geral; falta de interesse em habitação de interesse social/falta de sensibilidade; controle urbano; redução do papel do arquiteto; lacuna entre morador e arquiteto; leis e normas; questões financeiras; questões culturais; ausência de inovação tecnológica e interferências políticas.

A identificação dessas barreiras - e com certeza deve haver outras - visa despertar profissionais arquitetos, analistas de projeto, construtores e outros agentes intervenientes para o emprego do conceito de flexibilidade na concepção dos projetos, de forma a beneficiar ao usuário final.

\section{AGRADECIMENTOS}

À CAPES, pelo apoio recebido. Às pessoas que responderam ao formulário eletrônico da pesquisa e respectivas instituições: Universidade Federal de Santa Catarina (UFSC), Universidade Federal de Alagoas (UFAL), Universidade Federal do Rio de Janeiro (UFRJ), Universidade de São Paulo (USP), Universidade Vila Velha (UVV), Universidade Federal do Rio Grande do Sul (UFGRS), Universidade de Brasília (UNB), Universidade Federal do Paraná (UFPR), Universidade do Estado de Mato Grosso (UNEMAT), Universidade Estadual de Maringá (UEM), Universidade Federal de Mato Grosso (UFMT), Instituto Federal de Brasília (IFB). Também agradecemos à Elemental, empresa chilena, que apesar de não ser uma instituição de ensino, possui muita participação no meio acadêmico.

\section{REFERÊNCIAS}

ABREU, Rita; HEITOR, Teresa. Estratégias de flexibilidade na arquitetura doméstica holandesa: da conversão à multifuncionalidade. Disponível em: <http://infohabitar.blogspot. com.br/2007/01/estratgias-de-flexibilidade-na.html>. Acesso em: 10 de maio de 2013.

ARAVENA, Alejandro. Deixem o povo ampliar suas casas: depoimento [1 $1^{\circ}$ de outubro, 2012]. São Paulo: Revista Época. Entrevista concedida a Felipe Pontes. Disponível em: $<$ http://revistaepoca.globo.com/especial-cidades/noticia/2012/09/alejandro-aravena-deixem-opovo-ampliar-suas-casas.html>. Acesso em 14/10/2013.

ARAVENA, A. et al. Quinta Monroy. ARQ, Santiago, v. 57, p. 30-33, jul. 2004.

BARCELOS, K. A. Método para avaliação de projetos de habitação social: mobiliamento, espaciosidade e funcionalidade. 2011. 263 p. Dissertação (Mestrado em Engenharia de Edificações em Ambiental). Universidade Federal de Mato Grosso. Cuiabá, 2011.

BILAC, Elisabete. Superação da família nuclear cria novos modelos de relacionamento. [26 de janeiro de 2011]. São Paulo: Jornal Folha de São Paulo. Entrevista concedida a Juliana Vines. Disponível em: <http://m.folha.uol.com.br/equilibrioesaude/865781-superacao-da-familianuclear-cria-novos-modelos-de-relacionamento.html>. Acesso em 14/05/2013.

BRANDÃO, Douglas Queiroz. Diversidade e potencial de flexibilidade de arranjos espaciais de apartamentos: uma análise do produto imobiliário brasileiro. 2002. 443 p. Tese (Doutorado em Engenharia de Produção), Universidade Federal de Santa Catarina, Florianópolis, 2002.

Disposições técnicas e diretrizes para projeto de habitações sociais evolutivas.

Ambiente Construído, Porto Alegre, RS, v. 11, n. 2, p.73-96, 2011. Extraído de: $<$ http://www.scielo.br/scielo.php?pid=S1678-86212011000200006\&script=sci_arttext $>$ Acesso em: 10 de maio de 2013.

Habitação social evolutiva: aspectos construtivos, diretrizes para projetos e proposição de arranjos espaciais flexíveis. Cuiabá: CEFETMT, 2006. 
BRANDÃO, Douglas Queiroz; HEINECK, Luiz Fernando Mählmann. Estratégias de flexibilização de projetos residenciais iniciadas na década de 1990 no Brasil: tão somente um recurso mercadológico? Ambiente Construído, Porto Alegre, v. 7, n. 4, 2007. Disponível em: $<$ http://seer.ufrgs.br/ambienteconstruido/article/view/3755>. Acesso em: 12/07/2013.

CÂMARA BRASILEIRA DA INDÚSTRIA DA CONSTRUÇÃO. Desempenho de edificações habitacionais: guia orientativo para atendimento à norma ABNT NBR 15575/2013. Câmara Brasileira da Indústria da Construção. Fortaleza: Gadioli Cipolla Comunicação, 2013.

CAMPANHOLO, José Luiz. Construção personalizada: uma realidade do mercado. Téchne, $n$. 41, p.63-66, jul./ago. 1999.

CARVALHO, Regiane Lucinda de. Casa, comida e roupa lavada: fatores associados à saída do jovem brasileiro do domicílio de origem. Dissertação (Mestrado em Demografia) - Programa de Pós Graduação em Demografia, Universidade Federal Minas Gerais, Belo Horizonte, 2009.

CÍRICO, L. A. Por dentro do espaço habitável: uma avaliação ergonômica de apartamentos e seus reflexos nos usuários. 2001. 140 f. Dissertação (Mestrado em Engenharia de Produção) Programa de Pós-Graduação em Engenharia de Produção, Centro Tecnológico, Universidade Federal de Santa Catarina, Florianópolis, 2001.

DIGIACOMO, M. C. Estratégias de projeto para habitação social flexível. 2004. 163 f. Dissertação (Mestrado em Arquitetura) - Programa de Pós Graduação em Arquitetura e Urbanismo, Universidade federal de Santa Catarina, Florianópolis, 2004.

FINKELSTEIN, Cristiane Wainbert. Flexibilidade na arquitetura residencial: um estudo de caso sobre o conceito e sua aplicação. 2009. 172 f; Dissertação (Mestrado em Arquitetura) Programa de Pós Graduação em Arquitetura, Universidade Federal do Rio Grande do Sul, Porto Alegre, 2009.

JORGE, Liziane de Oliveira. Estratégia de flexibilidade na arquitetura residencial multifamiliar. 2012. 511 f. Tese (Doutorado em Arquitetura) - Programa de Pós Graduação em Arquitetura e Urbanismo, Universidade de São Paulo, São Paulo, 2012.

KAPP, Silke. Síndrome do estojo. In: Colóquio de Pesquisas em Habitação: Coordenação Modular e Mutabilidade. 4, 2007, Belo Horizonte. Anais... Belo Horizonte: EAUFMG, Grupo Morar de Outras Maneiras, 2007.

LEITE, F. L.; SCHRAMM, F. K.; FORMOSO, C. T. Gestão de empreendimentos habitacionais de interesse social: foco na gestão de requisitos do cliente e no projeto do sistema de produção. In: SATTLER, M. A.; PEREIRA, F. O. R. (Ed). Construção e Meio Ambiente. Porto Alegre: ANTAC, 2006 - (Coleção Habitare, v. 7)

MARROQUIM, F. M. G; BARBIRATO, G. M. Flexibilidade Espacial em Projetos de Habitações de Interesse Social. In: COLÓQUIO DE PESQUISAS EM HABITAÇÃO, 4., 2007, Belo Horizonte. Anais... Belo Horizonte: EAUFMG, Grupo Morar de Outras Maneiras, 2007.

MEIRA, G. R.; SANTOS, J. Y. R. Avaliação Pós-Ocupação em um Conjunto Habitacional: um estudo de caso. In: ENCONTRO NACIONAL DE TECNOLOGIA DO AMBIENTE CONSTRUÍDO, 7., 1998. Florianópolis. Anais... Florianópolis, 1998. p. 657-664.

MINISTÉRIO DAS CIDADES. Déficit habitacional no Brasil 2007. Ministério das Cidades, Secretaria Nacional de Habitação. Brasília, 2009. Disponível em < http://www.fjp.mg.gov.br/index.php/docman/cei/deficit-habitacional/109-deficit-habitacional no-brasil-2007/file>. Acesso em 14/01/2014.

MOSCHEN, P. D. C. Uma metodologia para personalização de unidades habitacionais em empreendimentos imobiliários multifamiliares. 2003. 193 f. Dissertação (Mestrado em Engenharia de Produção) - Programa de Pós-Graduação em Engenharia de Produção, Universidade Federal de Santa Catarina, Florianópolis, 2003.

PAYERAS, D. R. Levantamento dos resíduos sólidos gerados pela personalização não planejada de apartamentos: estudo de caso em Porto Alegre/RS. 2005. Dissertação (Mestrado 
Profissionalizante em Engenharia) - Curso de Pós Graduação em Engenharia Civil, Universidade Federal do Rio Grande do Sul, Porto Alegre, 2005.

SCHNEIDER, T; TILL, J. Flexible Housing: opportunities and limits. Theory. Vol 9. n 2. 2005. Disponível em: <http://wwww.jeremytill.net/Articles_files/flexible_arq_1.pdf> Acesso em: $12 / 12 / 2013$.

STRAPASSON, D. C. Flexibilidade em projetos de edificações de ensino superior: estudo de caso na UFPR. 2011. 112 f. Dissertação (Mestrado em Construção Civil) - Programa de Pós Graduação em Construção Civil, Universidade Federal do Paraná, Curitiba, 2011.

SZÜCS, Carolina P. Apropriação e modificação dos espaços da casa: inventário de soluções populares. In: NUTAU, 2., 1998, São Paulo. Anais... São Paulo: FUPAM, 1998.

SÜCZS, C. P.; PEREIRA, G. M. Adequação da Habitação de Interesse Social à Pessoa com Restrições. In: ERGODESIGN, 6, Bauru, 2006. Anais...CD-ROM.

TILLMANN, P. A. Diretrizes para a adoção da customização em massa na construção habitacional para baixa renda. 2008. 162 f. Dissertação (Mestrado em Engenharia) - Escola de Engenharia, Universidade Federal do Rio Grande do Sul, Porto Alegre, 2008.

TRAMOnTANO, M. Novos Modos de Vida, Novos Espaços de Morar: Paris, São Paulo, Tokyo. 1998. Tese (Doutorado em Arquitetura) - Faculdade de Arquitetura e Urbanismo, Universidade de São Paulo, São Paulo, 1998.

TRAMONTANO, M. Apartamentos, arquitetura e mercado: estado das coisas. In: Oficina Verticalização das cidades brasileiras, 2006, São Paulo. Disponível em: <http://www.nomads.usp.br/site/livraria/livraria.html.> Acesso em: 12/10 /2013.

TRAMONTANO, M. Habitações, metrópolis e modos de vida: por uma reflexão sobre a habitação contemporânea. Texto premiado no $3^{\circ}$ Prêmio Jovens Arquitetos: Primeiro Lugar na categoria Ensaio Crítico. São Paulo: Instituto dos Arquitetos do Brasil - SP / Secretaria de Estado da Cultura, 1998. Disponível em: http://www.nomads.usp.br/site/livraria/livraria_ artigos online01.htm. Acesso em: 12/10 /2013.

WEINSCHENCK, Julia Hunsche. Estudo da flexibilidade como mecanismo para a personalização de casas pré fabricadas: uma abordagem voltada para a industrialização de casas de madeira. 2012. 146 f; Dissertação (Mestrado em Arquitetura e Urbanismo) - Programa de Pós Graduação em Arquitetura e Urbanismo, Universidade Federal de Santa Catarina, Santa Catarina. 